\title{
Mechanism analysis, anti-corrosion techniques and numerical modeling of corrosion in energy industry
}

Hua Bai*

Petrochina Beijing Oil and Gas Pipeline Control Center, 9 Dongzhimen North Street, Dongcheng District, 100007 Beijing, PR China

Received: 29 January 2020 / Accepted: 21 April 2020

\begin{abstract}
Pipelines are the main transmission systems in energy industry thanks to its distinguished advantages on the low cost and high reliability. In order to ensure a safe and smooth pipeline operation, careful attentions must be paid to avoid structure failure and surface defect, which can both be attributed to corrosion. The past two decades has borne remarkable progress in our understanding of corrosion, with a tremendous increase in publications studying corrosion mechanisms and simulation. A review is constructed in this paper with three parts: mechanism analysis, anti-corrosion technique introduction, and numerical modeling and simulation. In mechanism, varieties of corrosions are found in engineering practice based on different electrochemical reaction conditions. The effect of temperature, $\mathrm{pH}$, pressure, flow properties and steel types are reviewed and the mutual influence of these factors is presented. Short introductions to protect the pipelines from these corrosion mechanisms are attached respectively and a thorough comparison is also conducted. Advantages and shortcomings of popular coating techniques are concluded based on published studies, and special focus is paid on the idea of cathodic protection. Modeling of the electrochemical reaction process is incorporated with transportation equations to govern the direct numerical studies on pipeline corrosions. Meanwhile, empirical models have been proposed to estimate corrosion growth from both deterministic and stochastic points of view. Finite element method has been proved to be an effective approach to simulate pipeline corrosion and further integrity analysis. Suggestions on future studies on the numerical modeling and simulation of pipeline corrosion have been provided on three directions: advanced multiphase flow simulation schemes, thermodynamic analysis and the usage of big data technique and machine learning algorithm. This paper is wished to be helpful for the scholars who are interested in the numerical studies on pipeline corrosion and the engineers who are supporting pipeline operation and integrity management.
\end{abstract}

\section{Introduction}

Pipeline transportation is playing an essential role in modern world to distribute oil and gas as the main energy source to our current society, which makes the safety and efficiency more concerned to reduce the costs at the same time of minimizing accidents. In all sustainable industries, pipeline is needed for injection, gathering, transportation, and distribution. Corrosion in pipelines can directly affect the efficiency and reliability performance of reservoir injection, fracturing, and recovery. Thus, both the analytical and numerical studies on pipeline corrosion are important for a clear and thorough understanding and description of flow in subsurface reservoirs. The high level requirement on pipeline reliability results in a strict limitation on the pipeline operation life. However, a fact exists that almost $40 \%$ of the current pipelines operating world-wide have reached their designed life (which is usually set as 20 years) [1].

\footnotetext{
* Corresponding author: baihuacup@163.com
}

As a result, numerous researches have been conducted in recent years to preserve the pipeline condition and to extend the residual pipeline life [2-14]. Structural integrity evaluation, which is among the common techniques involved, has attracted more and more attentions along with the increasing awareness of pipeline defects, which may cause pipeline leakage and further environmental risks. Cracks and corrosion pits are the main behaviors of pipeline defeat, and oil spills resulting from the defeat can be estimated at up to 2.5 billion gallons every year as calculated in [1].

The pipelines transporting oil and gas nowadays are commonly constructed with carbon steel materials to meet the economics requirements. Carbon steels have significant advantages on the low cost and wider availability as well as mechanical properties to help with the flexibility of routes and huge quantities of oil and gas transported. Meanwhile, the main shortage stands on the relatively lower corrosion resistance. Corrosion can be defined as the chemical process which attacks and degrades the pipe material into salts, oxides, and other compounds. Undergoing corrosion in 
metals and alloys may lead to the decrease in pipeline ductility, strength, and many other mechanical properties. Corrosion in underground buried pipelines can be spread widely in a high speed and responsible for most failures in pipeline operation. Plenty of studies have been proposed by oil companies and institutions worldwide in recent years to investigate the mechanism and growth rate of corrosion oil and gas pipelines. A survey on the publications recorded in Google Scholar with the topic "Pipeline Corrosion" has shown the continuously increasing trend of academic works (including journal papers, patents, and books) published in recent years, which indicates the remarkable efforts paid on this issue (Fig. 1).

A word cloud technique is applied to analyze the focus and attentions in these publications. As shown in Figure 2, the abstracts of 1000 publications recorded in Google Scholar with high citations have been collected and analyzed to extract the key words with more frequencies appeared in these abstracts. Except for our searching key word "Pipeline Corrosion" and common prepositions like "and" and "the", the popular words mentioned in this literature include descriptions on the materials related with corrosion like "steel", "carbon", "x80", "hydrogen", the terms related with corrosion like "cracking", "electrochemical", "strain", "failure", "cathodic", "polarization", and techniques to handle corrosion like "coating". Meanwhile, words like "model" and "simulated" with high frequency indicate the popularity of numerical simulations in the study of pipeline corrosion. It is interesting to see that the high frequency of words like "oil", "gas", "underground", and "soil" proves the trend that buried oil and gas pipelines have become the main target in current studies regarding pipeline corrosion, which is exactly the focus of this paper.

This paper is designed to review the publications from two aspects: mechanisms and modeling. In Section 2, different types of corrosion are concluded with corresponding mechanisms and a short introduction on prevention technique to each defect is provided. Afterwards, certain popular anti-corrosion techniques are analyzed and sorted into two types in Section 3: coating and cathodic protection with detailed explanations on the advantages and disadvantages of each technique. Furthermore, mathematical modelings to describe corrosion growth rate are reviewed in Section 4 with a classification of deterministic and stochastic models. Finally, numerical simulation algorithms are introduced and several conclusions and remarks are presented to enlighten future studies on this topic and help guide the practical operations in petroleum industry to control and minimize pipeline corrosion.

\section{Corrosion mechanism}

The degenerated condition of operating pipelines can be mostly attributed to the pipe material corrosion interacted with the external environment and internal working fluid. Both the pipeline itself and the related accessories, no matter made of metals such as cast iron, stainless steel and alloy steel, or non-metals such as plastic and glasses, can be affected by corrosion and cause huge amount of economic losses. To handle this big problem challenging our

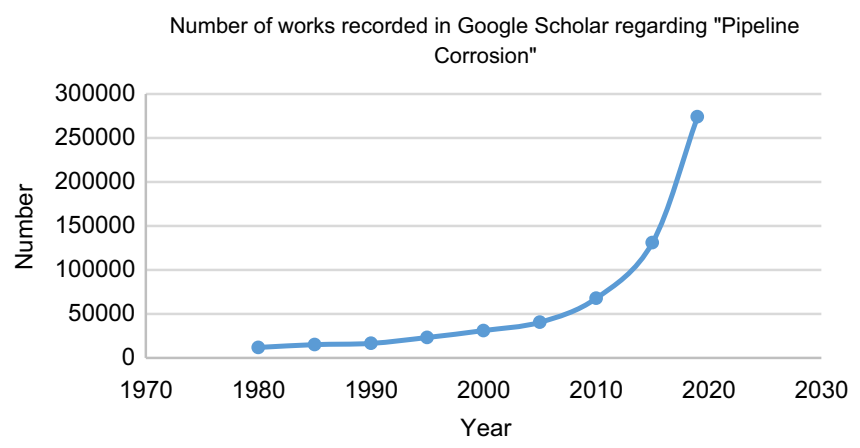

Fig. 1. Number of works recorded in Google Scholar regarding "Pipeline Corrosion".

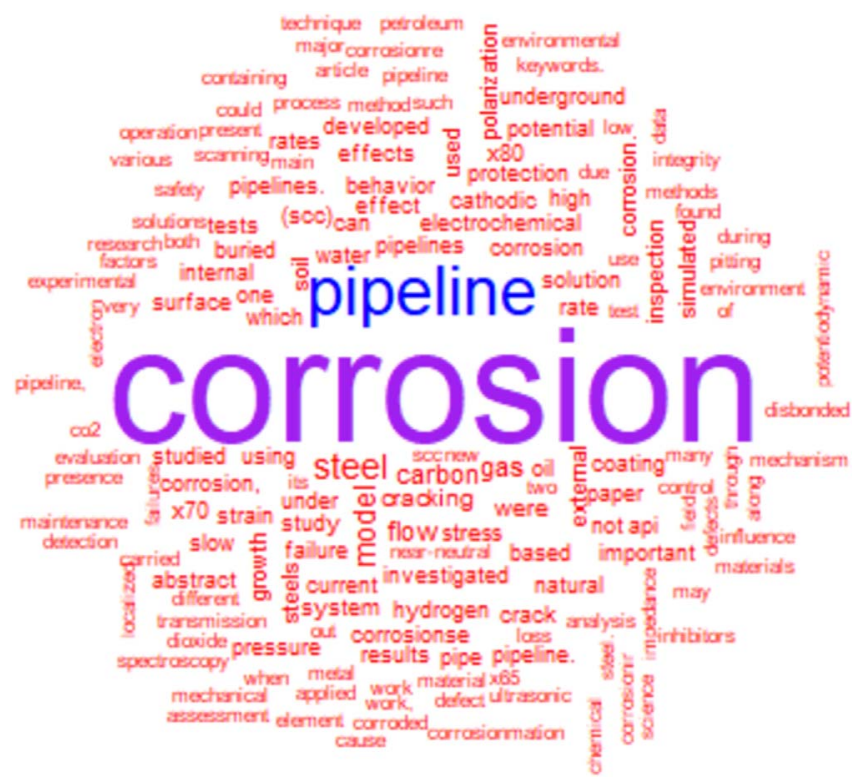

Fig. 2. Word Cloud analysis result of the 1000 publications with high citations.

society, designing the pipeline networks and selecting the most suitable material to build the pipe are becoming an extremely essential issue needing careful consideration in petroleum industry. The starting point in the designing and selecting process stands on the mechanism analysis and here we will review the key mechanisms of pipeline corrosion. It should be pointed out in prior that as an engineering problem, the name and definition of pipeline corrosion mechanisms can vary via proposed by different research directions, oil companies, institution groups, and even authors from different periods. In this paper, the authors try to conclude the mechanisms into certain types with the general names and definitions in literature with relatively higher citations, which may be treated as a more popular and public-accepted standard.

\subsection{Uniform pipe corrosion}

Uniform pipe corrosion refers to the material loss along the pipe surface in the pipelines, which may result in a uniform and continuing structure damage [15-18]. A common 
measurement method to describe the reaction and thinning rate is the simple penetration depth calculation on the pipe surface per year, usually in a unit of millimeters. This type of corrosion is the most common seen one, with relatively easier prevention techniques such as surface coatings and cathodic protection.

\subsection{Pitting corrosion}

Pitting corrosion refers to the localized but severe deterioration on a pipe's surface, which is located on a limited area but can cause fast cavity or pits formation [19-23]. In passive metal alloys, including aluminum and sometimes stainless steel, pitting corrosion can be easily found in pipelines with non-suitable material used to construct the pipe. The other mechanisms causing this type of corrosion can be concluded as aggressive chemical species causing penetration, mechanical hurts to the protective passive film and defects on material surface. As a severe corrosion with the ability to puncture the pipeline structure, it needs serious prevention techniques such as proper selection of the pipe material, enhancing anodic, and cathodic protection and specific treatment on the service environment including chemical concentration and temperature to keep resistant to pitting.

\subsection{Selective leaching}

When the alloy material constructing pipelines is formed with a noble metal or even more reactive elements, selective leaching can easily occur in pipeline operations [24, 25]. Also known as graphitic corrosion, this type of pipeline defect can cause material loss on the pipe surface with reactive element and result in structure strength loss and further failure in a premature time according to the design. As instructed in [26], nickel, cobalt, or zinc can be removed from copper alloys with electrochemical reactions and this is a typical case of selective leaching. An obvious observation can be found in the pipeline surface color, where the material density may also change at the same time. A common protection technique preventing this corrosion is the addition of tin can or aluminum in the pipeline surface materials in certain environmental conditions.

\subsection{Galvanic corrosion}

Galvanic corrosion is a type of pipeline defect resulted from the electrical connection of dissimilar alloys and other corrosion potentials where the metal is only working as an anode and will deteriorate $[27,28]$. As one of the so-called Under Deposit Corrosion (UDC), the concentration of aggressive components and the $\mathrm{pH}$ value will differ from the outside environment without deposit covered. The galvanic corrosion can be formed in the region between the under deposit area and the area without deposit [29]. Based on this mechanism, this type of corrosion can be prevented by applying the metal combination technique in the pipe construction, especially with species closer in the galvanic series to reduce such reaction. Insulation layer is also preferred to be place between the regions, as well as the help of cathodic surface.

\subsection{Crevice corrosion}

When oxygen availability varies at crevices in a pipeline, such as joints, crevice corrosion may occur as a result of accelerated reactions $[8,11]$. The anode in the electrochemical reaction will be played by the surfaces in need of oxygen. As reported in publications [10], crevice corrosion can be detected in an experiment designed to test pitting corrosion. The strong correlation between the two mechanisms can be shown by the tight link of the critical pitting potentials in various alloys and the susceptibility to crevice corrosion based on the laboratory measurement with exposures in $\mathrm{NaCl}$ solutions. Accordingly, this corrosion can be prevented by using welded joints instead of riveted joints in the pipe designing and construction [11].

\subsection{Intergranular deterioration}

A selective deterioration may occur when the surface's gain boundaries reach high activity, and this mechanism is defined as intergranular deterioration $[9,30]$. This high activity is commonly a result of high temperature, which can be seen as prone to corrosion. In practical operations on oil and gas pipelines, heated transportation, and welding heat can be the main cause of this material transformation, so that the main prevention technique is the selection of extra-low carbon stainless steel materials in order to ensure the maximum corrosion resistance when welding is required.

\subsection{Cavitation}

In some engineering cases, the working pressure in a pipeline can drop below the vapor pressure of the transported fluid and vapor pockets and bubbles may form as a result $[14,31,32]$. These vapor formations will collapse near the internal pipeline surface to cause cavitation damage, which is also called erosive corrosion. It can be concluded from the practical experiences that pump suctions, elbows, heat exchangers, valve seats, and tees can be the place with more possibility to see this cavitation, compared to other parts of pipelines with the same operation conditions. By reducing pressure gradients along the pipeline fluid transportations, cavitation can be controlled as well as air ingress can be avoided. Another technique is to introduce coatings on the pipeline surface and minimize excessive pressure drops.

\subsection{Stray current corrosion}

The stray current can be caused when the buried pipelines are placed near the electric railways or welding machines and local pitting and pin holes can occur on the internal surfaces at the location where the stray currents leave the pipe material $[12,13]$. Other underground electricity sources include cathodic protection and high voltage overhead. The current can be either DC or AC, which is decided by the electricity source. The current should be seen as a leakage as it deviates the intended path and prefers the alternative parallel route. Especially for pipelines and other storage and transportation facilities buried in subsurface or subsea soil, metallic structures can always perform as a 
preferred path with relatively lower resistance. For example, current strayed from the railway system can be picked up into the pipelines and then returned back to the rail after discharging to the soil. To handle this type of corrosion, controls on electricity leakage are the most common used technique and sometimes an additional protection system is also needed.

\subsection{Stress corrosion cracking}

The solubility of ionic species can be very low in the cases of very aggressive oxidizing environment and cracks will be formed and further grow into stress corrosion damage $[7,33]$. This type of corrosion is a severe problem faced by the petroleum industry, with the possibility to cause sudden failures in the pipeline operation especially under high temperature and tensile stress. If such stress grows larger than the designed threshold of the pipeline material, the cracks will grow rapidly and the failure may occur, particularly for pipes made of alloys. A general method to handle this corrosion is to limit the transportation load in the pipelines to keep the stress under the designed stress threshold.

\subsection{Special mechanisms}

Except for above typical types of corrosion occurred on buried oil and gas pipelines, certain specific mechanisms may also take control in corresponding special working environments. A very common special phenomena is the existence of high concentration of solids in the production fluids above a threshold of $10 \mathrm{wt} \%$. Corrections should be taken into account for the failure of infinite dilution theory and ionic strength should be introduced. A more accurate method is proposed in [34] to use activity coefficients for very high solid concentrations. It still waits for further investigation on the effect of precipitation of iron carbonate on surface electrochemistry where reaction happened. It has been reported in field experiments that corrosion rate can be highly reduced in a transported fluid with high solid concentration but a thorough and systematic theoretical study is still needed to analyze deeper.

As discussed in above sub-sections, temperature can draw impact on the corrosion process and modify the electrochemical reactions. However, the effect may vary for different $\mathrm{pH}$ conditions. For example, higher temperature will often lead to a larger corrosion rate in lower $\mathrm{pH}$ environment, but it has been found in [35] that in high $\mathrm{pH}$ conditions, the increasing of temperature will lead to an exceeded solubility of iron carbonate and relatively slow the reaction process.

Turbulent flow of transported fluid flow may accelerate the pipeline corrosion in low $\mathrm{pH}$ conditions due to the enhancement on species transport away from and towards the pipeline surface [36]. In high $\mathrm{pH}$ environments, the effect of turbulent flow mainly performs on interfering the formation of surface protection films and removes the iron carbonate scales from the place. Flow disturbances, including valves, expansion, bends, and constrictions, are often the source of turbulence with added shear stress. Furthermore, multiphase flow is common seen in oil and gas transportation pipelines with two or three phases existed.
Different flow patterns will result in various mechanisms controlling surface corrosion. In slug flow, mass transfer rate can be greatly increased and the large fluctuations will lead to extra shear stress towards the surface with removal of the protective scale and inhibitors [37].

Steel type constructing the pipeline is another factor effecting corrosion processes. In classical studies, only one type of pipeline steel is investigated in one study [38, 39] so that the proposed model is limited in the applications. Currently, multiple types of steels are taken into consideration and it has been found that the steel can be grouped into two sets: normalized steels and quenched and tempered steels. The parameters in empirical corrosion models are various for different types of steels. Except for the impact on electrochemical reactions, steel types may also influence the formation of protective scales and inhibitor adsorptions. For example, it has been verified that higher content of $\mathrm{Cr}$ in the pipeline materials can enhance the formation of protective scales but is harmful for some types of corrosion inhibitors.

\section{Anti-corrosion technique}

Corrosion in oil and gas pipelines can be seen as a phenomenon affected by multiple mechanisms and as a result of various physicochemical reaction processes. In order to mitigate or control the damage caused by corrosion to pipeline structures, plenty of techniques have been proposed regarding to different corrosion mechanisms as discussed in Section 2. In this part, some typical anti-corrosion techniques will be reviewed and concluded with explanations on the pros and cons of each technique based on the practical experience. As cathodic protection has become a very popular technique in petroleum industry to control pipeline corrosion, a subsection is designed to focus on this topic with details.

\subsection{Pipeline coatings}

Pipeline coating is the most common method to control corrosion with a long history of developments [40-42]. Various types of coating techniques have been proposed by different researchers and engineers, but the basic rule remains to control the electrochemical processes by minimizing the transport of water, carbon dioxide, and oxygen. The stability of the coating system should be ensured in extreme thermodynamic environmental conditions and the strength against corrosion damage should be guaranteed. Some typical types of coating systems reported in literature have been concluded, as shown in Table 1 with the pros and cons respectively.

It should be pointed out that coating systems using polyolefin with butyl adhesive has been optimized to overcome the listed disadvantages. A general method is to apply the dual-side extruded polyolefin instead of crosshead extruded polyolefin to improve the adhesion strength for steel materials and to resist the disbondment problem [43]. However, this technique appears to have certain shortages when it is difficult to be removed for repairing. Besides, multi-layer systems can be a good choice to 
Table 1. Coating systems used in oil and gas pipelines.

\begin{tabular}{|c|c|c|c|}
\hline Coating system & Pros & Cons & $\begin{array}{c}\text { Representative } \\
\text { literature }\end{array}$ \\
\hline $\begin{array}{l}\text { Coal tar enamel } \\
\text { coatings }\end{array}$ & $\begin{array}{l}\text { Fair adhesion to different types } \\
\text { of steel materials }\end{array}$ & $\begin{array}{l}\text { Risk to human health due to used } \\
\text { materials }\end{array}$ & {$[88,89]$} \\
\hline $\begin{array}{l}\text { Plant-applied tape } \\
\text { systems }\end{array}$ & $\begin{array}{l}\text { Good adhesion to different types } \\
\text { of steel materials }\end{array}$ & $\begin{array}{l}\text { Possibilities of blistering } \\
\text { occurring under stress }\end{array}$ & {$[90,91]$} \\
\hline $\begin{array}{l}\text { Polyolefin with butyl } \\
\text { adhesive }\end{array}$ & $\begin{array}{l}\text { Environmental friendship with less } \\
\text { pollution }\end{array}$ & $\begin{array}{l}\text { Low adhesion strength for steel } \\
\text { materials and disbondment } \\
\text { caused by cathodic protection }\end{array}$ & {$[92,93]$} \\
\hline $\begin{array}{l}\text { Epoxy (fusion- } \\
\text { bonded) }\end{array}$ & $\begin{array}{l}\text { Excellent adhesion to different types } \\
\text { of steel materials and good } \\
\text { resistance to disbondment caused by } \\
\text { cathodic protection }\end{array}$ & Limited resistance to abrasion & {$[94,95]$} \\
\hline $\begin{array}{l}\text { Metallic spray } \\
\text { coatings }\end{array}$ & $\begin{array}{l}\text { Low cost for various working } \\
\text { environments }\end{array}$ & $\begin{array}{l}\text { Possibility of low adhesion to } \\
\text { certain types of steel materials }\end{array}$ & {$[96,97]$} \\
\hline
\end{tabular}

improve the behavior of polyolefin system and epoxy systems with obvious enhancement on the resistance to disbondment and abrasion.

\subsection{Cathodic protection}

By turning the outside metal surface into a cathode in the electrochemical cell when reaction happens, pipeline corrosion can be controlled and this technique is generally defined as Cathodic protection, or simply CP [44-46]. Using a man-made anode with "sacrificial metal" which is more easily corroded is the basic idea of $\mathrm{CP}$ to protect the target pipeline metal instead of reducing the electrochemical reaction, as shown in Figure 3. For example, zinc coating can be used as sacrificial anode to protect the steel material from rust. CP systems can be applied in a wide range of structures in pipeline systems, and sometimes an extra external DC electrical power source is needed for long pipelines when passive galvanic $\mathrm{CP}$ is not enough to provide the current [47]. As reported in literature, CP systems have already been used in various types of storage and transportation systems, such as steel oil and gas pipeline, steel oil tanks, onshore, and offshore oil gathering system, pump stations and many others [44-50].

The electrochemical active galvanic anode with more negative electrode potential is often called as galvanic anode and attached to the vulnerable metal surface of the pipelines. The protected pipe metal often has a less active voltage than the galvanic anodes exposed to an electrolyte. In some extreme cases, $\mathrm{pH}$ can rise up to 13 and the stability of the passive protective layer should be preserved [51]. Galvanic systems can play this role due to the constant potential it can keep and the ability to provide a high initial current to restore passivity. The harmful negative Chloride ions can leave the steel in a direction to the positive anode along with this sacrificial current. In another word, restoration of the electrical environment is the goal of CP systems driven by potential difference between the cathode and anode, but not the constant polarization. Sometimes the

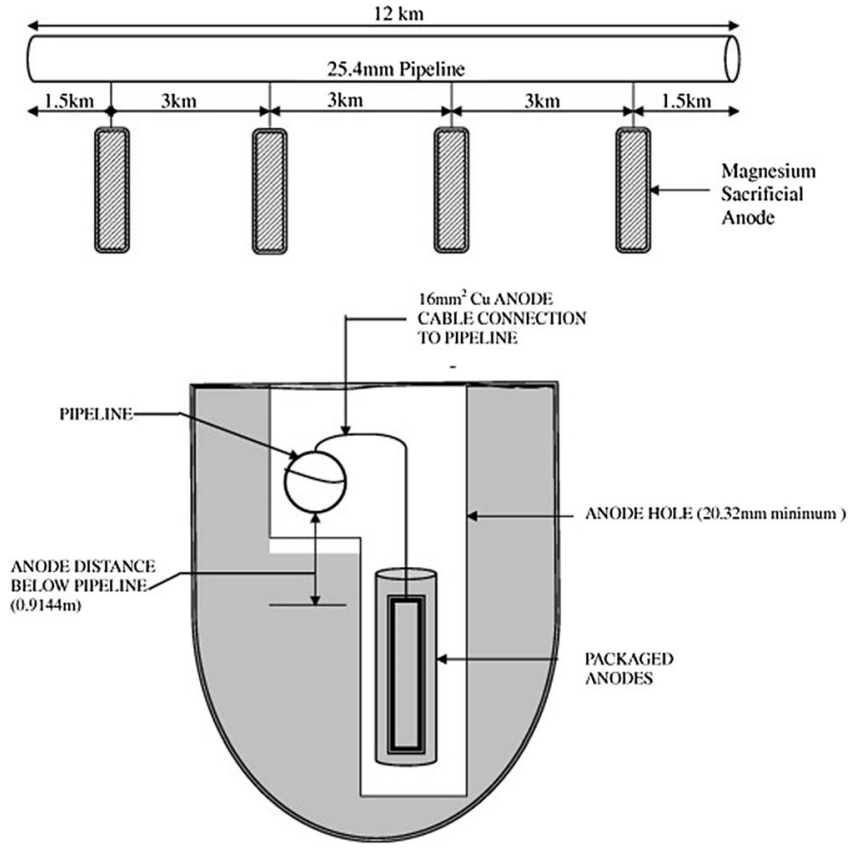

Fig. 3. A schematic to show the installation of the sacrificial anode [98].

steel surface is forced to be more negative (polarized) to push the generation of hydroxide ions on the surface.

Impressed current cathodic protection systems are another type of common used $\mathrm{CP}$ systems, which are also known as ICCP systems. A DC power source, often using a transformer-rectifier connected to AC power, is linked with anodes and this AC power source can be replaced by wind power or solar panels as alternative options. Anodes used in ICCP systems can be seen in various sizes and shapes, where solid rod shapes and tubular are often selected. The transformer-rectifier units used in ICCP systems are often designed with various features like remote control and integral current interrupters by the manufacturer. The input 
terminals are connected with the AC power cable, while the output DC positive cable is connected with the anodes on the surface targeted to be protected. Hybrid systems have become an incorporation technique for ICCP systems to make it easier to maintain the galvanic anodes with lower cost. Typically, the wired galvanic anodes are placed in arrays about $400 \mathrm{~mm}$ apart and initially powered. The anodes will then be attached to the pipeline surface steel and play a role of galvanic system when the power supply is taken away. Unlike sole ICCP system, constant polarization is no longer the goal of this system.

During the usage and development of $\mathrm{CP}$ systems, certain problems have been found and discussed. One side effect is the atomic hydrogen production if improper application of cathodic protection, which may lead to the hydrogen adsorption on the protected pipeline surface metal. The damage to weld and high hardness materials will be caused with the hydrogen embrittlement effect [52]. Generally, the hydrogen gas generated with the hydrogen atoms cannot penetrate the metal but the atoms themselves are too small to be blocked by the steel structure and in some cases embrittlement can then be caused. Another shortage of $\mathrm{CP}$ systems stands on the disbonding of cathodic protection coating from the pipeline surface. The increase of alkali ions and the rising of cathodic polarization can lead to disbonding [53]. Selective effects have also been found on the disbonding degrees of the coating types. Furthermore, a classical coating technique with long history, solid film backed dielectric coating has been discarded in recent engineering applications due to the high electrical resistivity, which may cause degeneration in the effectiveness of $\mathrm{CP}$ systems including shrinkable pipeline sleeves or polyethylene tapes. The protective current will be shielded or blocked by this film and cannot reach the underlying metal. To handle the disadvantages of general CP systems, proper operations are needed to avoid excessive polarization and corresponding excessive negative potentials.

\section{Numerical modeling and simulation}

In order to describe the corrosion conditions of the operated pipelines, numerical modeling and simulation are effective methods with no need to dig out the pipe on field and perform the measurement. It should be pointed out that the mathematical models cannot be capable of governing the corrosion performance well with considering all the parameters occurred in the electrochemical reaction process so that some neglecting of parameter relationships are needed in empirical equations [3, 54-59]. The development history of corrosion growth rate model is progressing along with including more and more effects and corresponding interactions of parameters. Currently popular models are designed to predict the corrosion growth rate with limited range of parameters considered and effective engineering environments. There has not been one simple model that can confidently announce to accurately describe all the corrosion mechanisms and include all the effective parameters in one equation. The limitation of established empirical models causes the need to accommodate multiple mechanisms in the numerical simulation and expand the range of applications. It is a good news for petroleum industry that the development of modern computation facilities and techniques make it possible to perform a reliable simulation for extremely complex environments considering varieties of corrosion mechanisms and meet the requirements of the large number and dimensions of the field data. In this section, models governing the corrosion process will be reviewed first and then we will look into the corrosion growth models from two points of view: deterministic models and stochastic models. Furthermore, numerical algorithms applied in the corrosion numerical simulation will be introduced and commented with the performance.

\subsection{Corrosion mechanism models}

In the viewpoint of corrosion process with ionic transport, the electro-physical-chemical mechanisms should include both the reaction and ionic transport. In [57], a simplified generalized mass transport equation is proposed considering reactive effects on the ionic concentration regardless of system tortuosity and porosity:

$$
\begin{aligned}
\frac{\partial}{\partial t} \psi_{l}+\nabla \cdot \Omega_{l}= & -\left(\sum_{i^{\prime}} v_{l^{\prime}} r_{i^{\prime}}+\sum_{m} v_{l m} r_{m}\right) \\
& -s\left(\sum_{i^{\prime}} v_{l^{\prime}}^{e} r_{i^{\prime}}^{e}+\sum_{m} v_{l m}^{e} r_{m}^{e}\right),
\end{aligned}
$$

where $\psi$ denotes the generalized concentration, $v$ denotes the chemical stoichiometric constants, $r$ denotes the reaction rate, $\Omega$ denotes the generalized flux and $s$ denotes the specific solid surface area of the reaction over solution volume. The subscript $i$ here means the secondary species, $m$ here means the independent species like mineral or precipitate with unit concentrations, and $l$ here means the arbitrary independent species. Generally speaking, the independent arbitrary species $l$ can be produced in an irreversible reaction where the reactant independent species cannot be produced to express the reaction products. The term " $i$ " here refers to the independent species involved in the reaction and can either be the same as or different with the species $l$. In cases where the stoichiometric constants $v_{l^{\prime}}$ and $v_{l^{\prime}}^{e}$ are all equal to 1, they are equivalent. $\psi$ can be calculated as,

$$
\Psi_{l}=c_{l}+\sum_{i} v_{l i} c_{i},
$$

where $c_{l}$ is the concentration of the $l$ species and $c_{i}$ is the concentration of the secondary species in the electrochemical reactions. The computation of other parameters can be referred to literature $[58,59]$. In practice, the independent solution species are often chosen in $\mathrm{Na}^{+}, \mathrm{Cl}^{-}, \mathrm{Fe}^{2+}, \mathrm{H}^{+}$, $\mathrm{O}_{2}(\mathrm{aq}), \mathrm{CO}_{2}(\mathrm{aq}), \mathrm{H}_{2}(\mathrm{aq}), \mathrm{FeCO}_{3}, \mathrm{Fe}$, and $\mathrm{H}_{2} \mathrm{O}$, while the secondary species can be selected from $\mathrm{OH}^{-}, \mathrm{CO}_{3}^{2-}$, $\mathrm{HCO}_{3^{-}}, \mathrm{H}_{2} \mathrm{CO}_{3}, \mathrm{FeOH}^{+}$, and $\mathrm{FeHCO}_{3}{ }^{+}$.

The electrochemical reaction process of corrosion process can be expressed in various equations to take considerations of different species. For example, if $\mathrm{CO}_{2}$ is playing the main contribution of aqueous corrosion on the pipeline 
surface made of carbon steel, the cathodic evolution of hydrogen and the anodic dissolution of iron can be expressed by [60]:

$$
\mathrm{Fe}+\mathrm{CO}_{2}+\mathrm{H}_{2} \mathrm{O} \rightarrow \mathrm{FeCO}_{3}+\mathrm{H}_{2}
$$

and it has been found that in comes cases $\mathrm{Fe}_{3} \mathrm{O}_{4}$ can be produced instead of $\mathrm{FeCO}_{3}$ under an environment with high temperature. It has also been found that it is more difficult to process hydrogen evolution with $\mathrm{H}_{2} \mathrm{CO}_{3}$ compared with species like $\mathrm{HCO}_{3^{-}}$, which can be proved by the electrode potentials from the thermodynamic point of view [61]:

$$
\begin{gathered}
E^{0}=-0.622 \mathrm{~V}(\mathrm{SCE}) \text { for } 2 \mathrm{H}_{2} \mathrm{CO}_{3}+2 \mathrm{e}^{-} \rightarrow \mathrm{H}_{2}+2 \mathrm{HCO}_{3}- \\
E^{0}=-0.856 \mathrm{~V}(\mathrm{SCE}) \text { for } 2 \mathrm{HCO}_{3^{-}}+2 \mathrm{e}^{-} \rightarrow \mathrm{H}_{2}+\mathrm{CO}_{3}^{2-} .
\end{gathered}
$$

The mechanisms for high-pH environment can be expressed in the following simple model as proposed in classical literature:

$$
\begin{gathered}
\mathrm{Fe}+\mathrm{H}_{2} \mathrm{O} \Longleftrightarrow \mathrm{FeOH}+\mathrm{H}^{+}+\mathrm{e}^{-} \\
\mathrm{FeOH} \stackrel{\text { rds }}{\longrightarrow} \mathrm{FeOH}^{+}+\mathrm{e}^{-} .
\end{gathered}
$$

However, in some later studies [62], the presence of $\mathrm{CO}_{2}$ can impact the anodic dissolution of iron where the carbonic species can play the role of chemical ligand and catalyze the iron dissolution. This different kinetics represented in laboratory experiments have been concluded into the following model for environment $\mathrm{pH}$ larger than 5 :

$$
\begin{gathered}
\mathrm{Fe}+\mathrm{CO}_{2} \Longleftrightarrow \mathrm{Fe}_{\mathrm{L}} \\
\mathrm{Fe}_{\mathrm{L}}+\mathrm{H}_{2} \mathrm{O} \Longleftrightarrow \mathrm{Fe}_{\mathrm{L}} \mathrm{OH}_{\mathrm{ad}}+\mathrm{H}^{+}+\mathrm{e}^{-} \\
\mathrm{Fe}_{\mathrm{L}} \mathrm{OH}_{\mathrm{ad}} \stackrel{\text { rds }}{\longrightarrow} \mathrm{Fe}_{\mathrm{L}} \mathrm{OH}_{\mathrm{ad}}^{+}+\mathrm{e}^{-} \\
\mathrm{Fe}_{\mathrm{L}} \mathrm{OH}_{\mathrm{ad}}^{+}+\mathrm{H}_{2} \mathrm{O} \Longleftrightarrow \mathrm{Fe}_{\mathrm{L}}(\mathrm{OH})_{2 \mathrm{ad}}+\mathrm{H}^{+} \\
\mathrm{Fe}_{\mathrm{L}}(\mathrm{OH})_{2 \mathrm{ad}} \Longleftrightarrow \mathrm{Fe}_{\mathrm{L}}(\mathrm{OH})_{2 \mathrm{sol}} \\
\mathrm{Fe}_{\mathrm{L}}(\mathrm{OH})_{2 \mathrm{sol}}+2 \mathrm{H}^{+} \Longleftrightarrow \mathrm{Fe}^{2+}+\mathrm{CO}_{2}+2 \mathrm{H}_{2} \mathrm{O} .
\end{gathered}
$$

Except for carbonic acid, HAc is another type of acid which can be the main source of hydrogen ions although it is also a weak acid with pKa is 4.76 at $25^{\circ} \mathrm{C}$. In some field experiences [63], the performance of HAc is named as Top-ofLine-Corrosion and shorted as TLC. The enhancement of HAc to the cathodic reaction has been validated in studies $[64,65]$ and the conclusive model can be expressed as:

$$
2 \mathrm{HAc}+2 \mathrm{e}^{-} \rightarrow \mathrm{H}_{2}+2 \mathrm{Ac}^{-} .
$$

Electrochemical kinetic equations can be used to describe the iron oxidation and ferrous ion reduction process, and Tafel equations are the typical models [57]:

$$
\begin{gathered}
i_{\mathrm{Fea}}=i_{\mathrm{Feref}}^{0} 10^{\frac{E-E_{\mathrm{Fe}}^{\mathrm{E} \text { cref }}}{b_{\mathrm{Fea}}}} \text { (iron oxidation), } \\
i_{\mathrm{Fec}}=-i_{\mathrm{Feref}}^{0} \frac{c_{3}}{c_{3 r e f}} 10^{\frac{-\left(E-E_{\mathrm{Fe}}^{\mathrm{E} \text { ref }}\right)}{b_{\mathrm{Fec}}}} \text { (ferrous ion reduction), }
\end{gathered}
$$

where the subscript "ref" here refer to the reference condition corresponding to the current density $i^{0}$ as well as the meaning in superscript, and $c$ is the concentration. $b$ is the Tafel slope, and can be predicted for different reactions. For example, for mechanisms shown in equation (5), the slope at $25^{\circ} \mathrm{C}$ is derived to be $2 \mathrm{RT} / 3 \mathrm{~F}=40 \mathrm{mV}$ [66].

\subsection{Deterministic corrosion growth models}

\subsubsection{Linear corrosion growth model}

The simplest deterministic corrosion growth rate model is expressed as [67]:

$$
h(t)=h_{0}+\dot{h \Delta} t
$$

where $h(t)$ denotes the corrosion depth at certain time $t, h_{0}$ denotes the initial corrosion depth, $h$ denotes the corrosion growth rate and $\Delta t$ denotes the time period considered for corrosion effect. It has been noticed that in [3] the period is denoted by $t$, which is confusing as $t$ also denotes the time in $h(t)$. It should be noted that as indicated in the formula, the corrosion growth rate is set as a constant, which means that the growth associated with each defect within the period of inspection is analyzed and determined by the measurement at the first time. Thus, $\dot{h}$ here is a deterministic corrosion growth rate to describe the linear behavior of corrosion growth and can be calculated by equation (10) with inspections from observations:

$$
\dot{h}=\frac{\mathrm{d} T_{2}-\mathrm{d} T_{1}}{T_{2}-T_{1}}
$$

where two sets of inspection data is proposed, and $\mathrm{d} T_{2}$ and $\mathrm{d} T_{1}$ denote the metal loss at the observation year $T_{2}$ and $T_{1}$. Compared with SVCT model, which is short for Single value corrosion growth model [68], the linear growth rate model is tested to be more accurate [69]. The corrosion growth used in SVCR model is also set to be the recommended value of NACE, i.e. $0.44 \mathrm{~mm} /$ year or 16 miles/year. This value is determined by an average of tracked inspections of defect depths in the evolution period to be analyzed. Thus, SVCR is a limited linear model with special application environment where the effect of age and corrosion depth can be ignored. The linear corrosion growth model is often regarded as signal matching from two runs of inspection signals. The pipeline corrosion growth rate can be very high if inspected for the severe corrosion conditions.

Meanwhile, another consideration in determining the growth rate is to check whether the observed features are occurred since the installation period or in the operation period. Generally, corrosion is considered to take place after oil or gas is transported through the target surface area in the operation life. It has been found in [70] that in some cases the corrosion growth will be speeded up after certain years of operation, which can be represented by a much higher corrosion growth rate calculated from the two inspections in a continuing period. An explanation is also provided in this paper for this inequivalent rate of new features that there is an inspection threshold of the tool and the initial defect may be not captured and recorded as 
zero. It has been proved that if correction on this issue has been performed, the corrosion rate increasing will be reduced to an acceptable and reliable speed. Corrosion rate resulting from equation (10) has been found to follow a normal distribution with the mean equal to the estimated value used in equation (9).

\subsubsection{Non-linear corrosion growth rate model}

In reliability estimation of the buried oil pipelines, corrosion rate should be considered to follow certain distribution laws. However, if linear corrosion growth model is applied, the difference between one defect and another is only in the mean value but the standard deviation depends just on the measurement tools errors. To handle this problem, the non-linear model should be taken into consideration in the pipeline operation evaluations. A common used model is proposed in [71]:

$$
h(t)=\alpha\left(t-t_{\text {ini }}\right)^{\vartheta},
$$

where $t$ denotes the current time, $t_{\text {ini }}$ denotes the initial corrosion time and $\alpha, \vartheta$ are two parameters representing soil and pipe properties. The challenge faced by this model stands on the existence of two ILI data sets which are not frequently used in companies.

\subsection{Probabilistic corrosion growth models}

Uncertainties can happen easily in realistic pipeline corrosion cases due to the complex and various working conditions and surrounding subsurface environments. Probability estimations become an effective approach by the statistic studies to describe the corrosion conditions in the buried pipelines. Generally, the data are assumed to be homogenous and the outside environment are set as consistent in the process.

\subsubsection{Markov model}

A Markov model with continuous time and nonhomogenous linear growth can be introduced in the modelling of buried oil and gas pipelines. By analyzing the observations of surrounding soil properties and coating types, corrosion evolution and rate distributions can be predicted using this model. Advantages of this model stand on the simple requirements of initial pitting depth distribution and soil-pipe parameters included in the model.

To mathematically model the Markov model, we first define a term $p_{m}\left(t_{0}\right)$ as the probability of the corrosion depth in a state at time $t_{0}$ equal to or less than $m$. Afterwards, the probability at time $t$ with corrosion depth equal to or less than $n$ can be calculated as:

$p_{n}(t)=\sum_{m=1}^{n} p_{m}\left(t_{0}\right)\left(\begin{array}{c}n-1 \\ n-m\end{array}\right)\left(\begin{array}{c}t_{0}-t_{\text {ini }} \\ t-t_{\text {ini }}\end{array}\right)^{\vartheta m}\left[1-\left(\begin{array}{c}t_{0}-t_{\text {ini }} \\ t-t_{\text {ini }}\end{array}\right)^{\vartheta}\right]^{n-m}$,

with the term can be calculated as:

$$
\left(\begin{array}{c}
n-1 \\
n-m
\end{array}\right)=\frac{(n-1) !}{(n-m) !(m-1) !},
$$

where $t_{\text {ini }}$ and $\vartheta$ denote the nonlinear corrosion evolution in an underground pipeline, $t_{0}$ denotes the time when the initial corrosion condition $p_{m}\left(t_{0}\right)$ is observed. The defect age and size may effect both the mean and variance of the corrosion depth distribution, which ensures that the Markov model can preserve more realistic soil and pipe properties and improve the reliability of its prediction. It has been found in previous literature that the incubation time of pipeline metal losses can always be chosen as 2.8 years, which is verified to be the mean beginning time of pitting for a wide class of soil types [72]. The corrosion rate distribution can be calculated as [21]:

$$
\begin{aligned}
f\left(v ; t_{0}, t\right)= & \sum_{m=1}^{N} p_{m}\left(t_{0}\right)\left(\begin{array}{r}
m+v\left(t-t_{0}\right)-1 \\
v\left(t-t_{0}\right)
\end{array}\right)\left(\frac{t_{0}-t_{\text {ini }}}{t-t_{\text {ini }}}\right)^{v m} \\
& \times\left[1-\left(\frac{t_{0}-t_{\text {ini }}}{t-t_{\text {ini }}}\right)^{v}\right]^{v\left(t-t_{0}\right)}\left(t-t_{0}\right),
\end{aligned}
$$

where $t$ is the time and $N$ is the total Markov states numbers.

\subsubsection{Monte-Carlo method}

Monte-Carlo (MC) method is well-known as a representative probabilistic parametric uncertainty investigation method, while the classic MC is often used as an uncertainty analysis to modify a deterministic calculation based on the ability to predict the probability of the nominal point to be at the alternative possible values. MC is sometimes more preferred due to the main advantage that no complicated mathematical analysis is required. In the meantime, the main shortage of MC method stands on the prolonged CPU time needed for getting an acceptable population statistical analysis. The corrosion rate is obtained by discrete random numbers generated in the model. An improved probability distribution is introduced in [73] to identify the corrosion initial time and the estimated corrosion depth data using the MC method is treated with $80 \%$ confidence.

\subsubsection{Time Dependent Generalized Extreme Value Distribution model (TD-GEVD)}

Time Dependent Generalized Extreme Value Distribution model is proposed to specific soil properties collected in southern Mexico and the time-varying rate distribution model can be suitable for general textural soil class [20]. A GEVD function is derived to express the distribution of corrosion pity growth rate along the subsurface oil and gas pipelines as:

$$
G(v)=\exp \left\{-\left[1+\zeta\left(\frac{v-\mu}{\sigma}\right)\right]^{-\frac{1}{\zeta}}\right\},
$$

where $v$ denotes the distribution variable, $\mu$ denotes the distribution location, $\sigma$ is the distribution scale and $\zeta$ is the shape parameter. The parameters introduced in this time-dependent model vary with the actual pitting period and can be calculated by: 


$$
\begin{gathered}
\mu(t)=-0.04816+(t-3.21819)^{-0.2411} \\
\sigma(t)=-0.53243+(t-3.42572)^{-0.0619} \\
\zeta(t)=-1.12501+(t-3.58835)^{0.0719}
\end{gathered}
$$

\subsubsection{Time Independent Generalized Extreme Value Distribution model (TI-GEVD)}

Compared with TD-GEVD, parameters in GEV corrosion rate distribution function are set to be constant as inspected at the initial time in TI-GEVD. This model is also applied in previous studies and the result is also acceptable [68]. Besides, it has been reported that the estimations using TI and TD-GEVD methods are similar to those of using Markov models for long intervals larger than 15 years.

\subsection{Corrosion simulation using finite element method}

Finite element method is an effective numerical algorithm to simulate corrosion process on buried pipelines and widely applied in researches [73-81]. Generally some assumptions are needed for a smooth and converged simulation, like linear-elastic property of the soil and elastic-plastic property of the pipelines. Besides, to focus on the corrosion propagation along the wall direction in pipe, the length of corrosion defect along the pipe direction is treated as unchanged. Another common seen pre-setting is a special treatment on boundary conditions, where an electrically isolated boundary is often set on the solution boundary and a free boundary is set for the steel/solution interface. A typical geometrical model is designed in $3 \mathrm{D}$ with corrosion defect reflected and simplification to 2D using symmetrical property, as shown in Figure 4 [4]. The finite element grids can be generated both on pipe materials and surrounding soils, and a typical meshing is provided in [77] using the commercial software ABAQUS (Fig. 5).

A FE simulation is conducted in [4] using COMSOL Multiphysics commercial software to study the corrosion with mechanic-electrical-chemical effect on X100 pipelines. Multiple physics are coupled, including various electrochemical reactions and stress analysis:

1. Mechanical elasto-plastic solid stress model:

$$
\sigma_{\text {yhard }}=\sigma_{\text {exp }}\left(\varepsilon_{\text {eff }}\right)-\sigma_{\mathrm{ys}}=\sigma_{\exp }\left(\varepsilon_{p}+\frac{\sigma_{e}}{E}\right)-\sigma_{\text {ys }},
$$

where $\sigma_{\text {yhard }}$ is defined as hardening function, $\sigma_{\exp }$ is the experimental stress function, $\varepsilon_{\text {eff }}$ is the total effective strain, $\varepsilon_{p}$ is plastic strain, $\sigma_{e}$ is effective stress, $E$ is Young's modulus of $207000 \mathrm{MPa}$ and $\frac{\sigma_{e}}{E}$ is elastic strain.

2. Electrochemical corrosion model:

$$
\begin{gathered}
i_{a}=i_{0, a} \exp \left(\frac{\eta_{a}}{b_{a}}\right) \\
i_{c}=i_{0, c} \exp \left(\frac{\eta_{c}}{b_{c}}\right) \\
\eta=\varphi-\varphi_{\text {eq }},
\end{gathered}
$$

where $i_{a}$ and $i_{c}$ denote the charge-transfer current density resulting from anodic and cathodic reactions respectively, and the subscript 0 denotes the exchange current density. $\varphi$ denotes the electrode potential, where the subscript eq denotes the equilibrium conditions, which can be calculated as [82-85]:

$$
\begin{gathered}
\varphi_{a, \mathrm{eq}}=\varphi_{a, \mathrm{eq}}^{0}+\frac{0.0592}{2} \log \left[\mathrm{Fe}^{2+}\right], \\
\varphi_{c, \mathrm{eq}}=\varphi_{c, \mathrm{eq}}^{0}+0.0592 \log \left[H^{+}\right]=-0.0592 \mathrm{pH} .
\end{gathered}
$$

3. Anodic reaction:

Elastic deformation : $\Delta \varphi_{a, \mathrm{eq}}^{e}=-\frac{\Delta P V_{m}}{z F}$,

Plastic deformation : $\Delta \varphi_{a, \mathrm{eq}}^{p}=-\frac{\mathrm{TR}}{z F} \ln \left(\frac{v \alpha}{N_{0}} \varepsilon_{p}+1\right)$.

Continuous elasto - plastic tension $: \varphi_{a, \mathrm{eq}}=$

$$
\varphi_{a, \mathrm{eq}}^{0}-\frac{\Delta P_{m} V_{m}}{z F}-\frac{\mathrm{TR}}{z F} \ln \left(\frac{v \alpha}{N_{0}} \varepsilon_{p}+1\right)
$$

where $\varphi$ denotes the anodic reaction equilibrium potential under deformations and the superscripts $e$ and $p$ represent elastic and plastic deformations respectively. The superscript 0 here denotes the standard equilibrium condition and $\Delta P$ denotes the excess pressure which is equal to $1 / 3$ of uniaxial tensile stress and the subscript $m$ means the elastic deformation limit [86]. Other thermodynamic parameters used in the above equations include: steel molar volume $V_{m}$, charge number $z$, absolute temperature $T$, Faraday's constant $F$ and orientation-dependent factor $v$.

4. Cathodic reaction:

$$
i_{c}=i_{0, c} \times 10^{\frac{\sigma_{\mathrm{Mises}} V_{m}}{6 F\left(-b_{c}\right)}},
$$

where $i_{0, c}$ denotes the hydrogen evolution exchange current density without strain or stress from outside, $\sigma_{\text {Mises }}$ denotes von Mises stress calculating using FE method and $b_{c}$ denotes the cathodic Tafel slope [86].

5. Electrical reactions:

$$
\begin{gathered}
\nabla i_{k}=Q_{k}, \\
i_{k}=-\sigma_{k} \nabla \varphi_{k},
\end{gathered}
$$

where $i$ denotes the current field distribution, $Q$ denotes a general source term, $\sigma$ is conductivity, and the subscript $k$ represents the index for solid or liquid respectively.

Finite element equation for integrity analysis is proposed in [77-80]: 

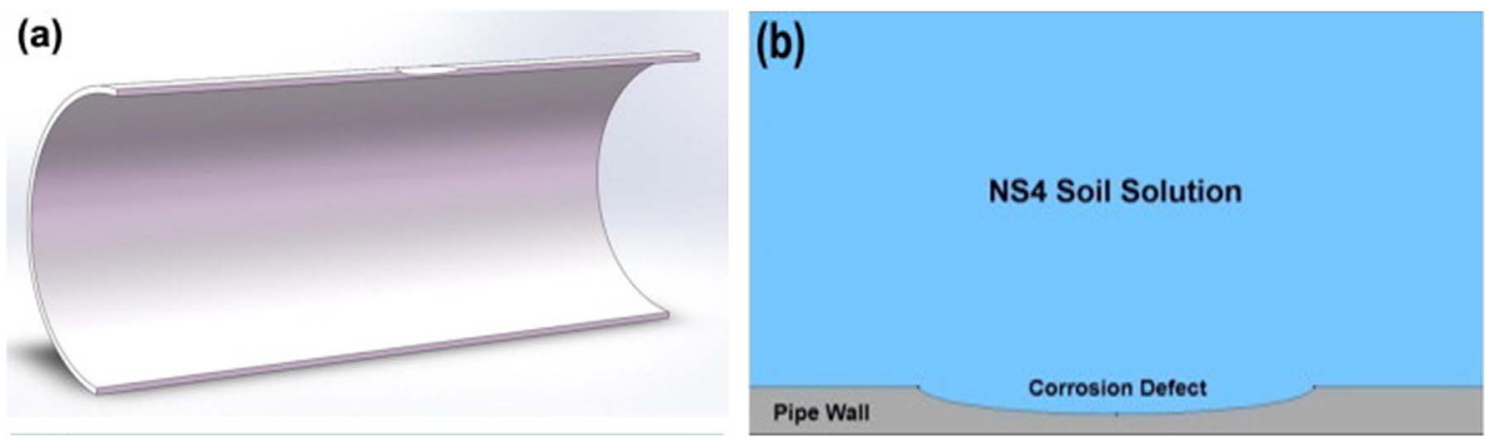

Fig. 4. The geometrical model to calculate corrosion defect using FE simulation in [4]: (a) 3D model and (b) 2D model.



Fig. 5. Finite element grids [77].

$$
[K][u]=\lambda[F],
$$

where $\lambda$ is the load factor, $[K]$ is the stiffness matrices, $[F]$ is the load matrix and $[u]$ is the replacement matrices. Equation (23) can also be transformed into the stabilization algorithm as:

$$
[K][u]+[C][u]=[F] .
$$

The viscous matrix $[C]$ is sufficiently large to avoid instantaneous collapse.

\section{Conclusion and remarks}

Pipeline may corrode over time in the operation life, which challenges the safe and reliable transportations of oil and gas and causes serious environmental risks. It can be concluded that there remains a lot to investigate on the corrosion mechanisms and anti-corrosion techniques. Determination of the corrosion type is prior to the corrosion prediction and further anti-corrosion practice, but careful analysis should be conducted to consider specific factors and thorough conditions. Selection of the pipe steel should be conducted based on a balance between corrosion reaction rate and protective scale formation rate. Suitable coating and cathodic protection remain challenging for extreme working conditions and complex species of transported fluids. For cases needing heat transport, a best heating temperature should be determined to control the enhancement of electrochemical reaction at the same time of reducing the viscosity.

Through the literature review and analysis of current investigations on pipeline corrosion, a significant progress can be found in the past decades on both the investigations of corrosion mechanisms and anti-corrosion techniques. However, the wide application of pipelines in energy industry and the high requirement on sustainability and reliability have imposed a strict restriction and plenty of expectations on corrosion related understandings and studies. The following remarks are concluded based on the author's working experience in energy transportation industry, for both the problems remaining in current investigations and potential directions in future researches:

1. It has been reported in literature that the properties of transported multiphase fluid flow have obvious impacts on the pipeline corrosion. However, there still remains a gap between the advanced direct multiphase flow simulation techniques and the flow pattern studies currently used in related researches. Certain techniques may include lattice Boltzmann methods, sharp interface models and diffuse interface models, which have been successfully applied in area like reservoir simulations and oil dehydrations [87], but are still in need to be incorporated with corrosion electrochemical reactions and corresponding ion kinetics.

2. The effects of temperature and $\mathrm{pH}$ conditions have been validated in previous studies, which support the potential of the application of advanced thermodynamic approaches on pipeline corrosion. Phase equilibrium investigations can be used to estimate the species concentrations in the transported fluid flows for each phase and this should be the first step for further transport studies. Molecular dynamics and flash calculations are effective methods to describe the accurate microscopic mechanisms behind the corrosion phenomenon and correct generalized empirical models. Thermodynamic consistency is also the priority to be checked in the algorithm generation to ensure the energy stability and unconditional convergence of the numerical simulation. 
3. Another problem challenging the studies of pipeline corrosion in modern petroleum industry is the tremendous amount of data produced and recorded in the pipeline operations. The complex and various working environments around buried pipelines make it necessary to inspect a large range of cases to develop an accurate and widely-applicable corrosion models. In the generation of empirical corrosion growth models, more factors are found to be effective and included in the model. As a result, big data techniques and machine learning algorithms can be introduced in this area to extract the factors and predict the corrosion conditions. Deep learning algorithm has been successfully used in phase equilibrium estimations in petroleum industry, and the further extensions to pipeline corrosion are expected.

\section{References}

1 Azevedo C.R.F. (2007) Failure analysis of a crude oil pipeline, Eng. Fail. Anal. 14, 6, 978-994.

2 Gloria N.B.S., Areiza M.C.L., Miranda I.V.J., Rebello J.M.A. (2009) Development of a magnetic sensor for detection and sizing of internal pipeline corrosion defects, NDT E Int. 42, 8, 669-677.

3 Vanaei H.R., Eslami A., Egbewande A. (2017) A review on pipeline corrosion, in-line inspection (ILI), and corrosion growth rate models, Int. J. Press. Vessels Pip. 149, 43-54.

4 Orazem M. (ed). (2014) Underground pipeline corrosion, No. 63, Elsevier, United Kingdom.

5 Xu L.Y., Cheng Y.F. (2013) Development of a finite element model for simulation and prediction of mechanoelectrochemical effect of pipeline corrosion, Corros. Sci. 73, 150-160.

6 Ilman M.N. (2014) Analysis of internal corrosion in subsea oil pipeline, Case Stud. Eng. Fail. Anal. 2, 1, 1-8.

7 Creager M., Paris P.C. (1967) Elastic field equations for blunt cracks with reference to stress corrosion cracking, Int. J. Fract. Mech. 3, 4, 247-252.

8 Oldfield J.W., Sutton W.H. (1978) Crevice corrosion of stainless steels: I. A mathematical model, Br. Corros. J. 13, $1,13-22$.

9 Hasan F., Iqbal J., Ahmed F. (2007) Stress corrosion failure of high-pressure gas pipeline, Eng. Fail. Anal. 14, 5, 801-809.

10 Wilde B.E., Williams E. (1971) The use of current/voltage curves for the study of localized corrosion and passivity breakdown on stainless steels in chloride media, Electrochim. Acta 16, 11, 1971-1985.

11 Brown S.A., Flemming C.A.C., Kawalec J.S., Placko H.E., Vassaux C., Merritt K., Payer J.H., Kraay M.J. (1995) Fretting corrosion accelerates crevice corrosion of modular hip tapers, J. Appl. Biomater. 6, 1, 19-26.

12 Bertolini L., Carsana M., Pedeferri P. (2007) Corrosion behaviour of steel in concrete in the presence of stray current, Corros. Sci. 49, 3, 1056-1068.

13 Zhu Q., Cao A., Zaifend W., Song J., Shengli C. (2011) Stray current corrosion in buried pipeline, Anti-Corros. Methods Mater. 58, 5, 234-237.

14 Young F.R. (1999) Cavitation, World Scientific, London, United Kingdom.

15 Edwards M., Ferguson J.F. (1993) Accelerated testing of copper corrosion, J. Am. Water Works Assoc. 85, 10, 105-113.
16 Liu G., Tree D.A., High M.S. (1994) Relationships between rotating disk corrosion measurements and corrosion in pipe flow, Corrosion 50, 8, 584-593.

17 Cole I.S., Marney D. (2012) The science of pipe corrosion: A review of the literature on the corrosion of ferrous metals in soils, Corros. Sci. 56, 5-16.

18 Sadiq R., Rajani B., Kleiner Y. (2004) Probabilistic risk analysis of corrosion associated failures in cast iron water mains, Reliab. Eng. Syst. Saf. 86, 1, 1-10.

19 Sheikh A.K., Boah J.K., Hansen D.A. (1990) Statistical modeling of pitting corrosion and pipeline reliability, Corrosion 46, 3, 190-197.

20 Caleyo F., Velázquez J.C., Valor A., Hallen J.M. (2009) Probability distribution of pitting corrosion depth and rate in underground pipelines: A Monte Carlo study, Corros. Sci. 51, 9, 1925-1934.

21 Caleyo F., Velázquez J.C., Valor A., Hallen J.M. (2009) Markov chain modelling of pitting corrosion in underground pipelines, Corros. Sci. 51, 9, 2197-2207.

22 Mao X., Liu X., Revie R.W. (1994) Pitting corrosion of pipeline steel in dilute bicarbonate solution with chloride ions, Corrosion 50, 9, 651-657.

23 Chaves I.A., Melchers R.E. (2011) Pitting corrosion in pipeline steel weld zones, Corros. Sci. 53, 12, 4026-4032.

24 Ha T.K., Kwon B.H., Park K.S., Mohapatra D. (2015) Selective leaching and recovery of bismuth as $\mathrm{Bi}_{2} \mathrm{O}_{3}$ from copper smelter converter dust, Separat. Purif. Technol. 142, 116-122.

25 Senapati P.K., Mohapatra R., Pani G.K., Mishra B.K. (2012) Studies on rheological and leaching characteristics of heavy metals through selective additive in high concentration ash slurry, J. Hazard. Mater. 229, 390397.

26 Bond A.M., Wallace G.G. (1983) Simultaneous determination of cadmium, cobalt, copper, lead, mercury and nickel in zinc sulfate plant electrolyte using liquid chromatography with electrochemical and spectrophotometric detection, $J$. Liq. Chromatogr. 6, 10, 1799-1822.

27 Van Boven G., Chen W., Rogge R. (2007) The role of residual stress in neutral $\mathrm{pH}$ stress corrosion cracking of pipeline steels. Part I: Pitting and cracking occurrence, Acta Mater. 55, 1, 29-42.

28 Zhang G.A., Yu N., Yang L.Y., Guo X.P. (2014) Galvanic corrosion behavior of deposit-covered and uncovered carbon steel, Corros. Sci. 86, 202-212.

29 Tan Y., Fwu Y., Bhardwaj K. (2011) Electrochemical evaluation of under-deposit corrosion and its inhibition using the wire beam electrode method, Corros. Sci. 53, 4, 12541261.

30 Li X., Shang C., Ma X., Gault B., Subramanian S.V., Sun J., Misra R.D.K. (2017) Elemental distribution in the martensite-austenite constituent in intercritically reheated coarsegrained heat-affected zone of a high-strength pipeline steel, Scrip. Mater. 139, 67-70.

31 Tullis J.P. (1989) Hydraulics of pipelines: Pumps, valves, cavitation, transients, John Wiley \& Sons, USA.

32 Provoost G.A. (1976) Investigation into cavitation in a prototype pipeline caused by water hammer, in: NASA STI/ Recon, Technical Report No. 78.

33 Was G.S., Ampornrat P., Gupta G., Teysseyre S., West E.A., Allen T.R., Sridharan K., Tan L., Chen Y., Ren X., Pister C. (2007) Corrosion and stress corrosion cracking in supercritical water, J. Nucl. Mater. 371, 1-3, 176-201. 
34 Anderko A. (2000) Simulation of $\mathrm{FeCO}_{3} / \mathrm{FeS}$ scale formation using thermodynamic and electrochemical models, in: Corrosion-National Association of Corrosion Engineers Annual Conference, NACE.

35 Wang S., George K., Nesic S. (2004) High pressure $\mathrm{CO}_{2}$ corrosion electrochemistry and the effect of acetic acid, in: Corrosion/2004, paper, 4375.

36 Nešic S., Solvi G.T., Enerhaug J. (1995) Comparison of the rotating cylinder and pipe flow tests for flow-sensitive carbon dioxide corrosion, Corrosion 51, 10, 773-787.

37 Nesic S., Pots B.F.M., Postlethwaite J., Thevenot N. (1995) Superposition of diffusion and chemical reaction controlled limiting currents-application to $\mathrm{CO}_{2}$ corrosion, J. Corros. Sci. Eng. 1, 3, 1-14.

38 De Waard C., Lotz U., Dugstad A. (1995) Influence of liquid flow velocity on $\mathrm{CO}_{2}$ corrosion: A semi-empirical model, in: Corrosion-National Association of Corrosion Engineers Annual Conference, NACE, USA.

39 Gray L.G., Anderson B.G., Danysh M.J., Tremaine P.R. (1990) Effect of $\mathrm{pH}$ and temperature on the mechanism of carbon steel corrosion by aqueous carbon dioxide, in: Corrosion/90, paper, 40.

40 Song F.M., Kirk D.W., Cormack D.E., Wong D. (2005) Barrier properties of two pipeline coatings, in: Corrosion, 2005, NACE International, Houston, USA.

41 Guidetti G.P., Rigosi G.L., Marzola R. (1996) The use of polypropylene in pipeline coatings, Prog. Organ. Coat. 27, 1-4, 79-85.

42 Delanty B., O’Beirne J. (1992) Major field study compares pipeline SSC with coatings, Oil Gas J. (United States) 90, 24.

43 Crosby T., Wolodko J., Tsaprailis H. (2016) Gap analysis of Canadian pipeline coatings: A review study, in: $N A C E$ International Corrosion Conference Proceedings, NACE International, p. 1.

44 Von Baeckmann W., Schwenk W., Prinz W. (1997) Handbook of cathodic corrosion protection, Elsevier, Houston, USA.

45 Chen X., Li X.G., Du C.W., Cheng Y.F. (2009) Effect of cathodic protection on corrosion of pipeline steel under disbonded coating, Corros. Sci. 51, 9, 2242-2245.

46 Shipilov S.A., Le May I. (2006) Structural integrity of aging buried pipelines having cathodic protection, Eng. Fail. Anal. 13, 7, 1159-1176.

47 Bushman J. B., PE Principal Corrosion Engineer. (2010) Corrosion and cathodic protection theory, Bushman \& Associates Inc., Medina.

48 Gummow R.A., Eng P. (2002) GIC effects on pipeline corrosion and corrosion control systems, J. Atmos. Sol.-Terr. Phys. 64, 16, 1755-1764.

49 Buchler M., Schoneich H.G. (2009) Investigation of alternating current corrosion of cathodically protected pipelines: Development of a detection method, mitigation measures, and a model for the mechanism, Corrosion 65, 9, $578-586$.

50 Du Y.X., Zhang G.Z. (2006) Regional cathodic protection in pump stations, Corros. Protect. -Nanchang 27, 8, 417.

51 Bertolini L., Pedeferri P. (2002) Laboratory and field experience on the use of stainless steel to improve durability of reinforced concrete, Corros. Rev. 20, 1-2, 129-152.

52 Louthan M.R. (2008) Hydrogen embrittlement of metals: A primer for the failure analyst, J. Fail. Anal. Prevent. 8, 3, 289-307.
53 Ihekwaba N.M., Hope B.B., Hansson C.M. (1996) Pull-out and bond degradation of steel rebars in ECE concrete, Cement Concrete Res. 26, 2, 267-282.

54 Stephens M., Nessim M. (2006) A comprehensive approach to corrosion management based on structural reliability methods, in: 2006 International Pipeline Conference. American Society of Mechanical Engineers, pp. 695-704.

55 Ahammed M. (1998) Probabilistic estimation of remaining life of a pipeline in the presence of active corrosion defects, Int. J. Pres. Vessels Pip. 75, 4, 321-329.

56 Teixeira A.P., Soares C.G., Netto T.A., Estefen S.F. (2008) Reliability of pipelines with corrosion defects, Int. J. Pres. Vessels Pip. 85, 4, 228-237.

57 Song F.M., Sridhar N. (2008) Modeling pipeline crevice corrosion under a disbonded coating with or without cathodic protection under transient and steady state conditions, Corros. Sci. 50, 1, 70-83.

58 Song F.M., Kirk D.W., Graydon J.W., Cormack D.E. (2004) Predicting carbon dioxide corrosion of bare steel under an aqueous boundary layer, Corrosion 60, 8, 736-748.

59 Song F.M., Kirk D.W., Graydon J.W., Cormack D.E. (2002) $\mathrm{CO}_{2}$ corrosion of bare steel under an aqueous boundary layer with oxygen, J. Electrochem. Soc. 149, 11, B479-B486.

60 Gileadi E., Kirowa-Eisner E. (2005) Some observations concerning the Tafel equation and its relevance to charge transfer in corrosion, Corros. Sci. 47, 12, 3068-3085.

61 Pourbaix M. (1966) Atlas of electrochemical equilibria in aqueous solutions, Pergamon Press, New York.

62 Nesic S., Thevenot N., Crolet J.L., Drazic D. (1996) Electrochemical properties of iron dissolution in the presence of CO2-basics revisited, in: Corrosion 96. NACE International.

63 Larrey D., Gunaltun Y.M. (2000) Correlation of cases of top of line corrosion with calculated water condensation rates, in: Corrosion 2000. NACE International.

64 Hedges B., McVeigh L. (1999) The role of acetate in $\mathrm{CO}_{2}$ corrosion: The double whammy, in: Corrosion 99. NACE International.

65 Garsany Y., Pletcher D., Hedges B.M. (2002) The role of acetate in $\mathrm{CO}_{2}$ corrosion of carbon steel: Has the chemistry been forgotten? in: Corrosion 2002. NACE International.

66 Carvalho D.S., Joia C.J.B., Mattos O.R. (2005) Corrosion rate of iron and iron-chromium alloys in $\mathrm{CO}_{2}$ medium, Corros. Sci. 47, 12, 2974-2986.

67 Din M.M., Ngadi M.A., Noor N.M. (2002) Improving inspection data quality in pipeline corrosion assessment, in: Proceedings of the 2009 International Conference on Computer Engineering and Applications.

68 Valor A., Caleyo F., Hallen J.M., Velázquez J.C. (2013) Reliability assessment of buried pipelines based on different corrosion rate models, Corros. Sci. 66, 78-87.

69 Dawson S.J., Wharf J., Nessim M. (2008) Development of detailed procedures for comparing successive ILI runs to establish corrosion growth rates, in: PRCI Project EC, pp. 1-2.

70 Gu B., Kania R., Keith K., Gao M., Coote R. (2003) Advances in corrosion growth analysis and future integrity assessment of pipelines, in: Corrosion 2003. NACE International.

71 Noor N.M., Ozman N.A.N., Yahaya N.O.R.D.I.N. (2011) Deterministic prediction of corroding pipeline remaining strength in marine environment using DNV RP-F101 (part A), J. Sustain. Sci. Manage 6, 1, 69-78. 
72 Velázquez J.C., Caleyo F., Valor A., Hallen J.M. (2009) Predictive model for pitting corrosion in buried oil and gas pipelines, Corrosion 65, 5, 332-342.

73 Duell J.M., Wilson J.M., Kessler M.R. (2008) Analysis of a carbon composite overwrap pipeline repair system, Int. J. Pres. Vessels Pip. 85, 11, 782-788.

74 Kiefner J.F., Kolovich K.M. (2007) Calculation of a corrosion rate using Monte Carlo simulation, in: Corrosion 200\%, NACE International, Houston, USA.

75 Lord W., Sun Y.S., Udpa S.S., Nath S. (1988) A finite element study of the remote field eddy current phenomenon, IEEE Trans. Mag. 24, 1, 435-438.

76 Kim W.S., Kim Y.P., Kho Y.T., Choi J.B. (2002) Full scale burst test and finite element analysis on corroded gas pipeline, in: 2002 4th International Pipeline Conference, American Society of Mechanical Engineers, Alberta, Canada, pp. $1501-1508$.

77 Liu P.F., Zheng J.Y., Zhang B.J., Shi P. (2010) Failure analysis of natural gas buried X65 steel pipeline under deflection load using finite element method, Mater. Design 31, 3, 1384-1391.

78 Ramm E. (1981) Strategies for tracing the nonlinear response near limit points, in: Nonlinear finite element analysis in structural mechanics, Springer, Berlin, Heidelberg, pp. 63-89.

79 Crisfield M.A. (1983) An arc-length method including line searches and accelerations, Int. J. Numer. Methods Eng. 19, 9, 1269-1289.

80 Liu P.F., Zheng J.Y. (2006) A Monte Carlo finite element simulation of damage and failure in $\mathrm{SiC} / \mathrm{Ti}-\mathrm{Al}$ composites, Mater. Sci. Eng. A 425, 1-2, 260-267.

81 Tao R., Moussawi A., Lubineau G., Pan B. (2016) Accurate kinematic measurement at interfaces between dissimilar materials using conforming finite-element-based digital image correlation, Opt. Laser. Eng. 81, 103-112.

82 Parkins R.N. (2000) A review of stress corrosion cracking of high pressure gas pipelines, in: Corrosion 2000. NACE International, p. 5.

83 King F., Jack T.R., Chen W., Wilmott M.J., Fessler R.R., Krist K. (2000) Mechanistic studies of initiation and early stage crack growth for near-neutral pH SCC on pipelines, in: Corrosion 2000. NACE International.

84 Bagotsky Vladimir S. (eds.) (2005) Fundamentals of electrochemistry, Vol. 44, John Wiley \& Sons, New Jersey, USA.

85 Park J.J., Pyun S.I., Na K.H., Lee S.M., Kho Y.T. (2002) Effect of passivity of the oxide film on low-pH stress corrosion cracking of API 5L X-65 pipeline steel in bicarbonate solution, Corrosion 58, 4, 329-336.

86 Gutman E.M. (1994) Mechanochemistry of solid surfaces, World Scientific Publishing Company, Singapore.

87 Zhang T., Sun S. (2019) A coupled Lattice Boltzmann approach to simulate gas flow and transport in shale reservoirs with dynamic sorption, Fuel 246, 196-203.

88 Kwun H., Kim S.Y., Choi M.S., Walker S.M. (2004) Torsional guided-wave attenuation in coal-tar-enamelcoated, buried piping, NDT E Int. 37, 8, 663-665.

89 Fred W., Lawn R.J. (1956) Coating compositions containing coal tar pitch and an epoxy ether resin. U.S. Patent No. 2,765,288.

90 Dempster W., Kellner J.D., Serra J.M., DeCoste L.D. (1994) U.S. Patent No. 5,300,356, U.S. Patent and Trademark Office, Washington, DC.

91 Roche M., Melot D., Paugam G. (2006) Recent experience with pipeline coating failures, J. Protect. Coat. Lin. 23, 10, 18.

92 Sloan R.N. (1967) Pipeline coatings, in: Control of Pipeline Corrosion (2001), 2nd ed., NACE International, Houston, TX, pp. 7-20.

93 Niu L., Cheng Y.F. (2008) Development of innovative coating technology for pipeline operation crossing the permafrost terrain, Construct. Build. Mater. 22, 4, 417-422.

94 Malik A.U., Andijani I., Ahmed S., Al-Muaili F. (2002) Corrosion and mechanical behavior of fusion bonded epoxy (FBE) in aqueous media, Desalination 150, 3, 247-254.

95 Doidjo M.T., Belec L., Aragon E., Joliff Y., Lanarde L., Meyer M., Bonnaudet M., Perrin F.X. (2013) Influence of silane-based treatment on adherence and wet durability of fusion bonded epoxy/steel joints, Prog. Org. Coat. 76, 12, 1765-1772.

96 Deshpande S., Sampath S., Zhang H. (2006) Mechanisms of oxidation and its role in microstructural evolution of metallic thermal spray coatings - case study for Ni-Al, Surf. Coat. Technol. 200, 18-19, 5395-5406.

97 Brito V.S., Bastos I.N., Costa H.R.M. (2012) Corrosion resistance and characterization of metallic coatings deposited by thermal spray on carbon steel, Mater. Design 41, 282288.

98 Lilly M.T., Ihekwoaba S.C., Ogaji S.O.T., Probert S.D. (2007) Prolonging the lives of buried crude-oil and naturalgas pipelines by cathodic protection, Appl. Energy 84, 9, 958-970. 